\title{
Private or Public Sector Oral Health Care Service Trends in Area with Agro Based Economy in Sri Lanka
}

\section{A Case Study in Mahiyanganaya Divisional Secretariat Area}

\author{
Y.M.S.S. Yapa ${ }^{1 *}$, S.N. Kumari², S.R. Jayasinghe ${ }^{2}$, T.H.N.G. Amaraweera ${ }^{3}$ \\ ${ }^{1}$ Postgraduate Institute of Medicine, University of Colombo \\ ${ }^{2}$ Department of Science and Technology, Faculty of Applied Sciences, Uva Wellassa University, Badulla, Sri Lanka. \\ ${ }^{3}$ Department of Applied Earth Sciences, Faculty of Applied Sciences, Uva Wellassa University, Badulla, Sri Lanka. \\ DOI: 10.29322/IJSRP.11.06.2021.p11446 \\ http://dx.doi.org/10.29322/IJSRP.11.06.2021.p11446
}

\begin{abstract}
Oral health is considered as an integral part of general health care system in Sri Lanka and operated through a well-organized network of institutes in both state and private sector. The public oral health system is driven by taxes and provided free of charge at the point of delivery. The private sector is mainly financed by the patient's out of pocket expenditure. Detailed investigations on patients' behavior on the selection of services offered by above two sectors are rare in Sri Lanka. The main aim of this study is to describe the factors affecting selection of private or public sector oral health care services in the divisional secretariat area Mahiyanganaya. A cross sectional descriptive study was carried out in government and private dental clinics in Mahiyangana divisional secretariat area using interviewer administered questionnaire. A total of 422 participants were qualified for the study including patients from private and public sector equally.
\end{abstract}

The socio demographic factors mainly age, gender, economic and education background of the patients may have significant influence in selection of oral health care services provider. Females predominantly used oral health care provided by both private (55.4\%) and public $(73 \%)$ sector. Younger population $(21-30$ y) showed a tendency to obtain oral health care facility provided by private sector $(25.1 \% ; \mathrm{n}=53)$ while middle age group $(31-40 \mathrm{y})$ preferred public sector $(29.4 \% ; \mathrm{n}=62)$. The patients with higher education background and higher family income (> Rs. 20001.00) generally opted private sector oral health care services. Perceived patient care relationship, perceived quality of oral health care services, perceived responsiveness of oral health care services and cost of treatment are important factors related to oral health care services when selecting either private or public sector. Patients were more satisfied with the functional quality of the private sector. The cost of treatment was the most discouraging factor for selection of private oral health care sector.

Patients' satisfaction for public oral health care sector can be enhanced via improving the accessibility, cleanliness of environment, selection of choice of provider and availability of dental equipment and materials. Introducing cost escalation mechanisms or cost regulation mechanisms will be vital for providing better service from the private oral health care sector.

Key Words: Selection of Oral Health Care Services, Mahiyanganaya Divisional Secretariat Area 


\section{INTRODUCTION}

Oral health care services in the world are organized and financed either by social health insurance, tax-based systems and out-ofpocket expenditure. Preventive and curative oral health services are available to the population via either private or public system in western industrialized countries (Oral Health Services, 2016, Malmö University, 2009).

In developing countries, public oral health care services are offered basic health and clinical services to the entire population through Ministries of Health from regional or central hospitals. Furthermore, African, Asian and Latin-American countries have a shortage of oral health professionals. In those low-income countries, almost half of the health spending is private. Furthermore, the private dental sector in those countries are small and mode of provision of private dental care being through solo practices (Malmö University, 2009). Among the South Asian countries, Sri Lanka holds a high standard of health care services including oral health (Govindaraj et al., 2014). Oral health care services in Sri Lanka are a part of Out Patient Department (OPD) in general health system which is driven by taxes including both direct and indirect payments. It provides oral health facilities to the community free of charge at the point of delivery. The private system is financed by the patients out of pocket expenses as well as the claims from insurance companies, but compared to out of pocket expenditure the insurance claims are minimal (De Alwis et al., 2011).

The private Oral health care system plays an important role in the delivery of oral health services, particularly in terms of outpatient care. This system is financed by the out-of-pocket expenses and claims from insurance companies. However, insurance claims are minimal compared to out-of-pocket expenditure (De Alwis et al., 2011). On average, $86 \%$ of total revenue to private health facilities in Sri Lanka comes from direct payments by patients (Govindaraj et al., 2014).

Private oral health care system in Sri Lanka is delivered both by full-time general dental practitioners and government-employed dental surgeons who do part-time private practice. Approximately, 795 dental surgeons are working in the private sector as full-time dental practitioners (Annual Health Bulatin, 2012). Selection of health services provided by the private sector has several advantages such as convenience, selection of desired specialist and continuation of treatment with the same doctor (Govindaraj et al., 2014). However, the cost for the medical treatment is the major concern in the private sector.

Major issues in the private oral health care system in Sri Lanka include; (i) eligibility of any dental surgeon registered under Sri Lanka Medical Council to enter into private sector, (ii) lack of supervision from Ministry of Health or by professional dental body, (iii) lack of minimum standard either in qualitative or quantitative perspectives and (iv) unregulated fees for the treatment. Due to unregulation of private dental clinic in Sri Lanka and absence of information flow from private dental practitioners to the central data base, proper records on the number of practitioners, number of patients and treated diseases are unavailable.

Factors affecting peoples' selection for oral care provider is highly complicated. Worldwide Patient related factors and service related factors are considered when selecting particular oral health care facility provider. The patient related factors include socio demographic factors, dental anxiety, income, distance to the clinic, the cost of treatment, clinic recommended by friends and waiting time (Eustaquio, et al., 2010, Brennan et al., 2008, Manski et al., 2001). The service related factors include efficiency, charisma, technical skills, pain management skills, human and other resources, relationship between oral health care staff and patient, quality of dental care and related environment (Brennan et al., 2008, Manski et al., 2001). These factors vary across geographic locations and demographic groups. Iqbal et al., 2014 described that there is a complex interaction between patients' choices and service providers' characteristics and that preferences vary for different individuals possessing a different cultural and socio-economic background.

However, several studies in different part of the world showed that the women tend to use more oral health care services from both private and public sector and elderly population tends to use more healthcare facility in general (Moshkelgosha et al., 2014, Pinto et al., 2014, Eustaquio, et al., 2010).

The key underlined factor for the use of oral health care services has depended upon each individuals income level in both developed and developing countries (Moshkelgosha et al., 2014, Ajayi \& Arigbede, 2012, Chu et al., 2001 Goedhart et al., 1996). The cost of treatment is mainly affected patients with lower socio-economic backgrounds (Chu et al., 2001, Goedhart et al., 1996). In addition, patients with lower education level also are more concerned about the cost of dental treatment. Study on oral health care service in the United Kingdom implied that the benefits of the private dental care were perceived mainly to be associated with easier access, longer contact time with patients and pleasant environment although it was more expensive (Hancock et al., 1999). Cost of delivered care is an important factor that determines selection of service provider (Moshkelgosha et al., 2014; Pinto et al., 2014).

The key underlying factor for the use of oral health care services depends on the income and education levels, regardless of different health care systems around the world (Moshkelgosha et al., 2014, Pinto et al., 2014). Distance and convenient appointment time were also more important for those living in more deprived area only when seeking non-aesthetic treatment (Moshkelgosha et al., 2014). Dental patients consider various factors when looking for non-aesthetic treatment (Moshkelgosha et al., 2014). However, recommendation and reputation of dentist and dental clinic played an important role when seeking aesthetic treatment by patients (Moshkelgosha et al., 2014). 
High quality service and concern for the patients' well-being are the most important factors when selecting dental clinics. Study based on the Riyadh City by Al-Johara \& Al-Hussyeen, 2010 and Collage of Dentistry, Taibah University, Saudi Arabia by Mahrous and Hifnawy, 2012 indicates that the quality of treatment plays an important role in for utilization of dental services. These studies further indicated that the high quality of dental care was offered by the private sector. A study on public perceptions and experiences on private and public oral health care service in the United Kingdom showed that greater satisfaction with certain aspects of private care than the public system, although the dentists' technical skills and pain management skills were equal (Hancock et al., 1999). Moreover, the post-operative complications are the most discouraging factor for selecting government clinics and most encouraging factor was the availability of friendly staff (Al-Johara \& Al-Hussyeen, 2010).

Explanation of the procedure before treatment is very important aspect in the patient-dentist satisfaction (Mahrous and Hifnawy, 2012). Communication skill and personality of the dentist (cheerful, smiling, friendly) are more important factors to maximize the patients' satisfaction (Petal, 2014, Al-Johara \& Al-Hussyeen, 2010). Studies also showed that the patients were dislike to have a dentist who begins treatment without any explanation (Rankin and Haris, 1985). Furthermore, the patient's first impression that is appearance, including clothing often has a lasting impact although additional contact may change these initial interpersonal perceptions. Study on public attitude towards selection of dental service by Moshkelgosha et al., 2014 identified the poor reputation has negative impact on the selecting oral health care sector.

Patient's perception of cleanliness, comfortable waiting area, privacy during the treatment procedure and procedures taken to protect them from the spread of infectious disease are very important determinant for patient satisfaction and selection of provider (Awliya, 2003). Quality of dental care and convenient appointment, were also most important factors while geographic location was the least important factor for selection of private sector oral health care services from intermediate school female students in Saudi (Jannati, 2013, Al Johara \& Al-Hussyeen, 2010).

As discussed earlier, oral health care system of Sri Lanka is a part of OPD services operated under general health care system in both private and public sector. Detail investigations have not been reported to study the factors affecting the selection of oral health care services provided by the private or public sector in Sri Lank, especially in regions with the agro based economy. However, several studies available on selection of private and public sector for the general health care services and utilization pattern of oral health care services.

Study on utilization patterns of oral health care services by mothers attending the antenatal clinic in Dehiwala Medical Officer of Health area showed that the ethnicity, religion, level of education and number of children the mother already have were significantly associated with utilization status of oral health care services during pregnancy (Wickramasinghe, 2011). The study further revealed that the majority of woman select private dental clinic $(61.9 \% \mathrm{n} 422)$ during pregnancy (Wickramasinghe, 2011).

Bollagala, 2010 showed that the majority of elders $(65.6 \%)$ who lived in fee levying homes used general practice while elders who lived in nonpaying homes used hospital dental clinics regularly in institutionalized elderly in Colombo Municipal Council area. Elders who lived in fee levying homes were had some level of education and occupation level, most of them were previously employed and everyone had a current income. Nearly $50 \%$ of the elders of paying homes had visited dental surgeon during the course of one year but there were $26.7 \%$ of elders who lived in nonpaying homes never visited a dental surgeon. The high cost of dental treatment was the main reason for the utilization of oral health care services. The difficulty in transportation and the nonavailability of an escort were the other common difficulties. Perera, 2001 was also confirmed that the financial difficulties as the major barrier for receiving the oral health care services among community living elders in Moratuwa MOH area. The same results were also reported by Pallegedara, 2003.

Detail investigations have been conducted to study the distribution of oral health care services and capacity building of oral health personnel in public and private sectors in Sri Lanka (De Silva et al., 2010, De Silva, 2012, Perera et al., 2012,). However, detail investigations have not been reported to study the factors affecting the selection of oral health care services provided by the private or public sector in Sri Lanka, especially in regions with the agro based economy. Therefore Mahiyanganaya divisional secretariat area in Badulla District was selected for this study.

Mahiyangana divisional secretariat area has been recognized as one of the divisional secretariat area in which the highest poverty level exists (The Performance Report and Annual Accounts of District Secretariat Badulla, 2013). The Oral health clinic operated at the OPD of Base Hospital-Mahiyangana is the public oral health care provider and further four private dental clinics are operating in area. The divisional secretariat area is predominantly characterized by agriculture and rural economics. The rural economy is adversely affected by the high percentage of dependency and the low level of per capita income. The majority of the labour force in the area has engaged in the agriculture industries, but most of them are not in a position even to satisfy the basic needs of their lives. The present study aimed to identify socio demographic and economic characteristics of patients seeking either private or public sector oral health care services and factors affecting selection of private or public sector oral health care services. 


\section{METHODOLOGY}

A cross sectional descriptive study design was adapted. Eligible patients, who were visited to public or private dental clinics in the divisional secretariat area, Mahiyanganaya during the study period were taken as study population. The formula for calculating a population proportion with absolute precision was used for calculation of the sample size. Among four private dental clinics, two patients from each were selected randomly as candidate for study in each day. For public oral health clinics, eight participants from public oral health care sector were selected during OPD working hours randomly in each day. During 27 days, 211 patients were selected for each sector and totally 422 participants were considered for the study. Patients over 18 years of age, who were attending the oral health care services included into this study. For patients less than 18 years of age; the parents or guardians accompanying the child patients were taken as the study informants. Questionnaire was designed on basic demographic and social information about the participant to collect the data. For instance, data on age, gender, civil status, education level, occupation, family income, mode of transport were recorded.

Data obtained from the questionnaire was coded and cross checked for errors. Then, the data was analyzed using IBM SPSS Statistics (version 21.0) software. Frequency tables were used to identify the distribution of the choice of oral health care service according to the socio demographic factors. Chi-square analysis was applied to assess the relationship between socio demographic factors and the choice of the patient and significance level was considered as 1 percent for all indicators accept age (5 percent).

\section{RESULTS OF THE STUDY}

The study was conducted to investigate the factors associated with the use of public and private oral health care services in the agroeconomics divisional secretory area, Mahiyangana. Reliability is basically the credibility of the data collected by the researcher. The reliability demonstrates that the data collected is in accordance with the procedures; it is accurate and has the ability of replication. In this study Cronbach Alpha is used to test a construct's reliability. Overall Cronbach Alpha reliability coefficient for all items is 0.897 and this value is highly acceptable \& satisfactory.

\section{a. Socio Demographic Factors}

Frequency distribution and results of chi-square analysis of socio demographic factors on choice of oral health care service among private and public sector were illustrated in Table 1. Age of the patient and selection of oral health care services indicates that age group of 21-30 used more oral health care facilities (28.8\%) while followed by age group of 31-40 (24.2). In this age group, oral health care facility provided by private $(14.3 \%)$ and public $(14.5 \%)$ sectors used equally. Further, age group of 31-40 tends to use more public oral health care services $(13.4 \%)$ than private. Results of the chi-squared $(\mathrm{p}<0.05)$ indicates that there is a significant relationship between age and the selection of the oral health care service.B. Use of Simulation software

There are numbers of software available which can mimic the process involved in your research work and can produce the possible result. One of such type of software is Matlab. You can readily find Mfiles related to your research work on internet or in some cases these can require few modifications. Once these Mfiles are uploaded in software, you can get the simulated results of your paper and it easies the process of paper writing.

Among 422 candidates, overall female participation (64.9\%) was more in this study. Female were more used public (36.5\%) oral care health service than the private (28.4\%) sector oral health care service. However, male patients were mostly selected private sector $(21.6 \%)$ than the public sector $(13.5 \%)$. According to the Chi-square test, $(p<0.01)$ there is a statistically significant association between the gender and selecting oral health care service.

According to the Table 1, most of the married people used public (42.6\%) sector oral health care service. Among unmarried people, most of them used private $(68.8 \%)$ sector health care service. Further, among widowers, most of them were taking oral health care service provided by the public sector $(88.9 \%)$. Further, there is a significance relationship between the civil status and the choice of oral the health care service based on the results of chi-squared test $(\mathrm{p}<0.01)$. In the sample, majority of the patients were studies up-to GCE (O/L) (42.8\%) and among them, more patients are used public sectors $(23.3 \%)$ than private $(19.5 \%)$ sector. Those who have passed GCE (A/L) and had diploma/degree holders' patients used more private sector oral health care services. The level of education and selection of oral health care sector are having a significance relationship $(\mathrm{p}<0.01)$. Around $54 \%$ patients were unemployed and they were having approximately equally choice among private and public sector oral health care service. Therefore, there is no significant relationship between the occupation and the selection between public and private sector dental clinic.

Monthly family income may effect on choice of oral health care provider. People with family income less than Rs. 10,000 and family income in between Rs 10,001 and Rs 20,000 more select the public sector oral health care provider. However, patients who are having family income more than Rs. 20,001, select the private sector oral health care services (18.7\%). There is a statistically significant association between family monthly income level and selection of oral health care service provider $(p<0.01)$. Monthly family income low patients usually choosing the public sector outpatient department (OPD) service other than high income groups are selecting private OPD service. This study shows the statistically significant association between distances from home to relevant dental clinic 
and selection of oral health care service provider $(\mathrm{p}<0.01)$. Patients who are living more than $5 \mathrm{~km}$ away to sector provider were having the choice of using public sector $(41.2 \%)$ oral health care service. Further, patients who are living in between 0 to 5 km distance away from the clinic were more willing to use private sector health service.The patients who are having private vehicle selected more private sectors to fulfill their oral health care requirements $(23.8 \%)$, whereas patients who were used public transport, tend to obtain public sector $(44.3 \%)$ services. According to this, selection of oral health care service provider depends on mode of transport used by the patients $(\mathrm{p}<0.01)$.

Table 1: Frequency distribution and chi-square analysis of socio demographic factors on choice of oral health care service among private and public sector

\begin{tabular}{|c|c|c|c|c|}
\hline \multicolumn{2}{|c|}{ Variable } & \multicolumn{2}{|c|}{ Mode of the health care service } & \multirow{2}{*}{$\begin{array}{l}\text { P-value (Chi- } \\
\text { square test) }\end{array}$} \\
\hline & & $\begin{array}{c}\text { Public } \\
\text { Frequency }(\%)\end{array}$ & $\begin{array}{c}\text { Private Frequency } \\
(\%)\end{array}$ & \\
\hline \multirow[t]{8}{*}{ Age (Years) } & $1-10$ & $0(0.0)$ & $1(0.2)$ & \multirow[t]{8}{*}{0.025} \\
\hline & $11-20$ & $15(3.6)$ & $18(4.3)$ & \\
\hline & $21-30$ & $61(14.5)$ & $60(14.3)$ & \\
\hline & $31-40$ & $61(14.5)$ & $41(9.7)$ & \\
\hline & $41-50$ & $34(8.1)$ & $48(11.4)$ & \\
\hline & $51-60$ & $24(5.7)$ & $38(9.0)$ & \\
\hline & $61-70$ & $10(2.4)$ & $4(1.0)$ & \\
\hline & $71-80$ & $5(1.2)$ & $1(0.2)$ & \\
\hline \multirow[t]{2}{*}{ Gender } & Male & $57(13.5)$ & $91(21.6)$ & \multirow[t]{2}{*}{0.001} \\
\hline & Female & $154(36.5)$ & $120(28.4)$ & \\
\hline \multirow[t]{3}{*}{ Civil Status } & Unmarried & $24(5.7)$ & $53(12.6)$ & \multirow[t]{3}{*}{0.000} \\
\hline & Married & $179(42.6)$ & $155(36.9)$ & \\
\hline & Widow & $8(1.9)$ & $1(0.2)$ & \\
\hline \multirow{4}{*}{$\begin{array}{l}\text { Education } \\
\text { Level }\end{array}$} & Below GCE O/L & $62(14.7)$ & $40(9.5)$ & \multirow[t]{4}{*}{0.000} \\
\hline & GCE O/L & $98(23.3)$ & $82(19.5)$ & \\
\hline & GCE A/L & $46(10.9)$ & $63(15.0)$ & \\
\hline & Diploma/Degree & $5(1.2)$ & $25(5.9)$ & \\
\hline \multirow[t]{5}{*}{ Occupation } & Unemployed & $113(26.8)$ & $115(27.3)$ & \multirow[t]{5}{*}{0.464} \\
\hline & Non- Professional & $72(17.1)$ & $59(14.0)$ & \\
\hline & Semi-Professional & $21(5.0)$ & $32(7.6)$ & \\
\hline & Professional & $1(0.2)$ & $1(0.2)$ & \\
\hline & Retired & $4(0.9)$ & $4(0.9)$ & \\
\hline \multirow{3}{*}{$\begin{array}{l}\text { Family } \\
\text { Income }\end{array}$} & Less than $10,000 /-$ & $81(19.4)$ & $55(13.2)$ & \multirow[t]{3}{*}{0.001} \\
\hline & $10,001-20,000$ & $83(19.9)$ & $74(17.7)$ & \\
\hline & More than 20,001/- & $47(11.2)$ & $78(18.7)$ & \\
\hline \multirow{3}{*}{$\begin{array}{l}\text { Distance from } \\
\text { home to clinic }\end{array}$} & $0-2 \mathrm{Km}$ & $11(2.6)$ & $27(6.4)$ & \multirow[t]{3}{*}{0.003} \\
\hline & $2-5 \mathrm{Km}$ & $26(6.2)$ & $38(9.0)$ & \\
\hline & $>5 \mathrm{Km}$ & $174(41.2)$ & $146(34.6)$ & \\
\hline \multirow{3}{*}{$\begin{array}{l}\text { Mode of } \\
\text { Transport }\end{array}$} & Public & $179(44.3)$ & $100(24.8)$ & \multirow[t]{3}{*}{0.000} \\
\hline & Private & $21(5.2)$ & $96(23.8)$ & \\
\hline & None & $2(0.5)$ & $6(1.5)$ & \\
\hline
\end{tabular}

\section{b. Factors related to select public and private oral health care providers}

Table 2 shows reason for the last dental visit in public and private sector oral health care services. Majority patients (85.85\%) were visited to the clinics in last time to obtain the non-esthetic treatment. However, their selection of visit does not depend on public and private sector wise. When considering the esthetic treatment, it was more common to visit to the private oral health care service 
provider. Results of chi- squared analysis reveals that selection of either public or private oral health care sector depend on the patients' reasons for visit $(\mathrm{p}<0.01)$.

Table 2: Distribution of sample according to reason for the dental visit in public and private sector oral health care services

\begin{tabular}{lccc}
\hline Reason for visit & \multicolumn{1}{c}{ Oral Health Care Sector } & $\begin{array}{c}\text { Total } \\
\text { Frequency (\%) }\end{array}$ \\
\cline { 2 - 4 } & $\begin{array}{c}\text { Public } \\
\text { Frequency } \\
(\% \text { from public) }\end{array}$ & $\begin{array}{c}\text { Private } \\
\text { Frequency } \\
(\% \text { from private })\end{array}$ & \\
\hline Esthetic & $27(16.77)$ & $1(0.96)$ & $28(9.21)$ \\
\hline Non esthetic & $130(80.74)$ & $131(91.60)$ & $261(85.85)$ \\
\hline Routine checkup & $4(2.48)$ & $11(7.69)$ & $15(4.93)$ \\
\hline Total & $161(100)$ & $143(100)$ & $304(100)$ \\
\hline
\end{tabular}

Patients' perception regarding the relationship between oral healthcare staff and patent, environment of the clinic and availability of resources of clinic among the private and public oral health care sectors were illustrated in Table 3. 41.67\% of patients were more satisfied regarding the communication skills of the dentist in private oral health care sector. There was a statistically significant association for patients' perception regarding communication skills of dentist in private and public sector oral health care services ( $\mathrm{p}$ $<0.01$ ). Similarly, $38.96 \%$ of patients were more satisfied regarding the communication skills of the assistants in private oral health care sector. Meantime, $36.36 \%$ patients were satisfied in the public sector. There was a statistically significant association between patients' perception regarding the communication skills of the dental assistants in private and public sector oral health care services $(\mathrm{p}<0.01)$. Moreover, $37.86 \%$ of patients were more satisfied regarding the ability to get necessary information from reception or from the staff in private oral health care sector. Meantime $36.29 \%$ of patients were satisfied in that of the public sector. There was a statistically significant association between patients' perception regarding the ability to get necessary information from reception or from the staff in private and public sector oral health care services $(\mathrm{p}<0.01)$.

Table 3: Patients' perception regarding the relationship between oral healthcare staff and patent, environment of the clinic and availability of resources of clinic among the private and public oral health care sectors

\begin{tabular}{|c|c|c|c|c|c|}
\hline \multicolumn{2}{|c|}{ Patients' perception regarding } & \multicolumn{3}{|c|}{ Number of patients visited (total \%) } & \multirow{2}{*}{$\begin{array}{l}\text { Chi-squared } \\
\text { value } \\
\text { (p_value) }\end{array}$} \\
\hline & & Private & Public & Total & \\
\hline \multirow{2}{*}{$\begin{array}{l}\text { communication skills of } \\
\text { the dentist }\end{array}$} & Satisfied & $32(8.08)$ & $150(37.88)$ & $182(45.95)$ & \multirow{2}{*}{$\begin{array}{l}139.37 \\
(0.000)\end{array}$} \\
\hline & $\begin{array}{l}\text { More } \\
\text { Satisfied }\end{array}$ & $165(41.67)$ & 49 (12.37) & $214(54.04)$ & \\
\hline \multirow{2}{*}{$\begin{array}{l}\text { communication skills of } \\
\text { the Dental Assistants }\end{array}$} & Satisfied & $47(12.21)$ & $140(36.36)$ & $187(48.60)$ & \multirow{2}{*}{$\begin{array}{l}89.347 \\
(0.000)\end{array}$} \\
\hline & $\begin{array}{l}\text { More } \\
\text { Satisfied }\end{array}$ & $150(38.96)$ & $48(12.47)$ & $198(51.40)$ & \\
\hline \multirow{2}{*}{$\begin{array}{l}\text { ability to get necessary } \\
\text { information from the } \\
\text { reception or staff }\end{array}$} & Satisfied & $48(12.53)$ & $139(36.29)$ & $187(48.8)$ & \multirow{2}{*}{$\begin{array}{l}89.347 \\
(0.000)\end{array}$} \\
\hline & $\begin{array}{l}\text { More } \\
\text { Satisfied }\end{array}$ & $145(37.86)$ & $51(13.32)$ & $196(51.2)$ & \\
\hline \multirow{2}{*}{$\begin{array}{l}\text { clean environment of the } \\
\text { dental clinic }\end{array}$} & Satisfied & $184(46.58)$ & $93(23.54)$ & $277(70.1)$ & \multirow{2}{*}{$\begin{array}{l}95.505 \\
(0.000)\end{array}$} \\
\hline & Not Satisfied & $15(3.80)$ & $103(26.07)$ & $118(29.9)$ & \\
\hline \multirow[t]{2}{*}{ access to dental clinic } & Satisfied & $176(42.62)$ & $110(26.63)$ & $286(69.2)$ & \multirow{2}{*}{$\begin{array}{l}42.534 \\
(0.000)\end{array}$} \\
\hline & Not Satisfied & $34(8.23)$ & $93(22.52)$ & $127(30.8)$ & \\
\hline \multirow{2}{*}{$\begin{array}{l}\text { Availability of equipment } \\
\text { and other facilities in } \\
\text { dental clinic }\end{array}$} & Satisfied & $184(45.43)$ & $121(29.88)$ & $305(75.3)$ & \multirow{2}{*}{$\begin{array}{l}61.911 \\
(0.000)\end{array}$} \\
\hline & Not Satisfied & $15(3.70)$ & $85(20.99)$ & $100(24.7)$ & \\
\hline
\end{tabular}


According the Table 3, 46.58\% of patients were satisfied regarding the cleanliness of dental clinic in private oral health care sector. However, $26.07 \%$ of the public sector patients were not satisfied with the cleanliness of dental clinic. There was a statistically significant association between patients' perception regarding the cleanliness of dental clinic in private and public sector oral health care services $(\mathrm{p}<0.01)$. In addition, $42.62 \%$ of the patients were satisfied with the access to reach the dental clinic in private sector. However, $22.52 \%$ of public sector patients were not with the access. Further, chi-squared analysis revealed that there was an association between patients' perception regarding the access to reach the dental clinic in private and public sector oral health care services $(\mathrm{p}<0.01)$. The study shows that the $45.43 \%$ of patients were satisfied with the availability of equipment and other facilities in the private sector. While, in the public sector, it was $29.88 \%$. Further, patients' perception regarding the availability of equipment and other facilities depends on the private and public sector oral health care services wise $(\mathrm{p}<0.01)$.

Table 4 shows Patients' perception regarding the quality factor of treatment from the private and public oral health care sectors. According to the study, $42.93 \%$ of patients were more satisfied regarding consultation, examination and treatment by the dentist in the private oral health care sector. Meantime, 33.99\% of patients were satisfied with that of public sector. There was a statistically significant association between patients' perception regarding the consultation, examination and treatment by the dentist in private and public sector oral health care services ( $\mathrm{p}<0.01$ ). Similarly, $41.67 \%$ of patients were more satisfied regarding the consultation time duration with the dentist in the private oral health care sector. Only $32.83 \%$ of patients were satisfied in public sector consultation time duration. Chi-squared results shows that patients' perception regarding patients' consultation time duration depends on private and public sector oral health care services wise $(\mathrm{p}<0.01)$.

Maintaining privacy and attention and respects paid on their health by staff are important factors to be maintain in oral healthcare sector. According to the study, $38.56 \%$ of patients were more satisfied regarding the maintaining privacy during examination and treatment in private oral health care sector and it was in the public sector is $13.49 \%$. Also, association is significant in between patients' perception regarding the maintaining privacy during examination and treatment in private and public sector oral health care $(\mathrm{p}<0.01)$.

41.67\% patients informed that health care staff in the private sector paid high attention and respects to them, however, this value is very low in public sector (12.37). In addition to this, patients' perception regarding attention and respects paid on their health by staff was statistically varied according to the private and public sector oral health care services $(\mathrm{p}<0.01)$.

Table 4: Patients' perception regarding the quality factor of treatment from the private and public oral health care sectors

\begin{tabular}{llcccc}
\hline Patients' & & \multicolumn{2}{c}{ Number of patients visited (total \%) } & Chi-squared \\
value (p_value)
\end{tabular}


According to the distribution of patients' satisfaction regarding the ability of received service from dentist and other staff in this study (Table 4), $97.5 \%$ of patients satisfied with the service received by them from oral health care team in private sector. However, $52.6 \%$ of the public sector patients were not satisfied with the service received by them from oral health team in public sector. There was a statistically significant association between patients' satisfaction with regards to services they received between private and public oral health care sector $((\mathrm{p}<0.01)$. Moreover, $78.8 \%$ of patients were more satisfied on revisit to the current dental clinic in private oral health care sector. $87.9 \%$ of patients were satisfied to revisit public oral health care sector. There was a statistically significant association between patients' perception on feeling to revisit the current dental clinic in private and public sector oral health care services $((\mathrm{p}<0.01)$.

\section{c. Compares the reasonable cost of oral health care services in private sector}

Figure 1 illustrates the level of satisfaction on cost for oral health care services in private sector. $42.36 \%$ of patients were satisfied with cost of the private sector oral health care service and $38.91 \%$ of patients were not satisfied. According to the chi-squared analysis revealed that there is a significant impact on level of satisfaction on cost for oral health care services in private sector ( $\mathrm{p}<$ $0.01)$.

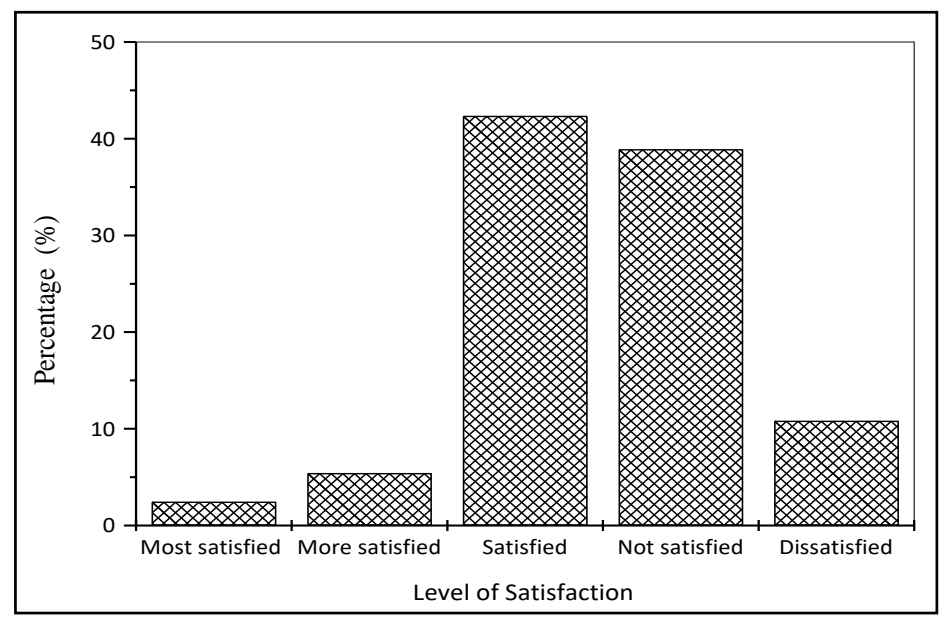

Figure 1: Level of satisfaction on cost for oral health care services in private sector

\section{DISCUSSION}

The main objective of this study was to describe the factors affecting utilization and selection of private or public sector oral health care services in the agriculture based low-income setting. Information on social-demographic characteristics, patients' perception regarding available facilities at the dental clinic, responsiveness, nature of received oral care services, the quality of treatment, and quality of oral health care sector environment, the relationship between patients and health care staff and the cost of treatment were collected.

\section{a. Socio demographic factors related in selection of oral health care services}

Among 422 candidates, majority of them was female patients and most of them were visited to private clinic. This was mentioned that, a study conducted in 2011 showed that the most of pregnant mothers used more private oral health care than public sector at Dehiwala MOH area in Sri Lanka (Wickramasinghe, 2011). In additionally, the studies on use of public and private dental services by adults in the state of Minas Gerais, Brazil showed that the women tend to use oral health care services from both private and public sector (Pinto et al., 2014). Similar results were also observed by several other studies (Moshkelgosha et al., 2014, Eustaquio, et al., 2010).

The study reveals that age is another influence factor to select private and public clinics. Some studies conducted in 2010 and 2003 in Sri Lanka have also confirmed that the elderly age groups use the lowest percentage of oral health care facilities due to financial difficulties, difficulty in transportation and the non-availability of an escort (Bollagala, 2010, Pallegedara, 2003, Perera, 2001). Moshkelgosha et al., 2014 shows that the age group of 30-40 years used more oral health care services $(58 \%$; $\mathrm{n}=232)$ from the study of Shiraz in south of Iran. The present study also proves more utilization of oral health care services by younger age group 
both private and public clinics equally likely while lesser utilization by elderly age groups mainly they do not care about their oral health and due to financial difficulties.

Study showed a statistically significant association between education level and selection of oral health care service provider. Study conducted in 2011 also showed the association between level of education and utilization status of oral health care services during pregnancy at Dehiwala MOH area in Sri Lanka (Wickramasinghe, 2011). Furthermore, a research showed that the educated institutionalized elderly population of Colombo Municipal Council area more often used private oral health care facility (Bollagala, 2010). The present study also proved the more utilization of private sector oral health care service by the patients with higher education level. This may be due to educated people have lot of difficulties to get treatment from public sector due to time constraint resulted by their high status of the job in society (Moshkelgosha et al., 2014). They can easily access the service in private oral health care sector. Additional, poor literate people having low-income jobs; they have to select public oral health care sector without any alternation (Moshkelgosha et al., 2014).

The patients who have low monthly income usually select the public sector outpatient department (OPD) service while the patients who have reasonable income select private OPD service in Sri Lanka (Varatharajan et al., 2005). This trend was also observed in oral health care services obtained by the elderly population of Colombo, Sri Lanka (Bollagala, 2010) and Minas Gerais, Brazil (Pinto et al., 2014). Further, this study showed that family monthly income level depends on the selection of oral health care service and high-income peoples tends to visit private sector more. Additionally, mode of transport was influence of selection of oral health care service. This may correlate to the income of the family and education level of the patients as discussed previously.

Previous studies showed that the distance of the dental clinic from patients' homes was less important when selecting oral health care service provider. Patients tend to travel more for aesthetic treatment and patient with higher education level tend to travel more to get the service from desired service provider (Moshkelgosha et al., 2014). Study conducted in general hospital Polonnaruwa showed that $47.4 \%$ of the outpatient dental clinic patients have bypassed the local oral health care institutes (Abeysekara, 2010). The patients attended dental clinic while on a visit to Polonnaruwa for some other purpose. The present study at Mahiyanganaya DS area (Table 1) showed the distance from participant resident and how it affects the selection of oral health care service utilize. Patients who live more than $5 \mathrm{Km}$ away to sector provider selected both private and public sector oral health care services. Further, Moshkelgosha et al., 2014 showed that the patients were more likely to travel to a longer distance and pay more when they seeking aesthetic treatment. The present study also proved the similar trend for utilization of oral health care service for aesthetic and nonaesthetic treatments. Overall, study was showed that those who have high family income and having professional jobs preferred to use private transport facilities to visit private clinics and majority of them are in younger females.

\subsection{Important Factors Related to the Selection of Private or Public Sector Oral Health Care Services}

Communication skill and personality of the dentist were significant factors to get the patients satisfaction (Petal, 2014; Mahrous and Hifnawy, 2012, Al-Johara \& Al-Hussyeen, 2010). The current study (Table 3) implied that the patients were most satisfied with the communication skills of the dentist and dental assistants in private sector oral health care services. Additionally, Rankin and Haris, 1985 pointed out that the patients were dislike to have a dentist who begins treatment without any explanation. According to the AlJohara \& Al-Hussyeen, 2010, availability of friendly staff was the most encouraging factor for the patient who received treatment in the public clinic $(\mathrm{p}<0.0001)$. The present study also implied that the communication skills of the dentist and dental staff and ability to get necessary information from reception are the more encouraging factor for the selection of oral health care services by the private sector.

Awliya, 2003 pointed out that the patient perception of cleanliness and procedures taken to protect them from the spread of infectious disease are important factors in oral health care service. Further, Al Johara \& Al-Hussyeen, 2010 also showed that the high quality of dental care was the most encouraging factor $(\mathrm{p}<0.009)$ for the selection of private sector oral health care services from intermediate school female students in Saudi. According to the present study, patients' perception regarding the cleanness of dental clinic and easy access to reach the dental clinic are a significant factors to the choice of service provider $(p<0.05)$. This was proved that the study based on public sector oral health care in India indicates that the majority of patients (97\%) were satisfied with easy access to the dental clinic in public oral health care sector (Patel, 2014).

Study based on patients' perception on OPD services at Vavuniya District, Sri Lanka showed that private OPD services had more quality equipment (Akilendran, 2014). While showing the patients' perception regarding the availability of equipment and other facilities was an affecting factor to the objective and it further illustrated that $45.83 \%$ of patients' were satisfied with the availability of equipment and other facilities in the private sector and satisfaction rate of public sector is $29.88 \%$.

Doctor's consultation and treatment play an important role when selecting oral health care services (Mahrous and Hifnawy, 2012, Hancock et al., 1999). A study at Vavuniya District, Sri Lanka by Akilendran, 2014 also showed that the consultation of doctors and friendly treatment were high in private OPD services than the public. Further, Study on public attitude towards selection of 
dental service by Moshkelgosha et al., 2014 identified the poor reputation has a negative impact on the selecting oral health care sector. Further, Hancock et al., 1999 showed that the patients tend to select private oral health care treatment in the United Kingdom since patients were satisfied with the consultation time duration of dentist in the private sector $(50 \%$, $\mathrm{n}=1402)$. Moreover, Ensuring the privacy of treatment was a major aspect in nature of received oral health care services (Mahrous and Hifnawy, 2012). According to the current study also revealed that patients' perception regarding doctor's consultation, examination and treatment, consultation time duration and patients' perception regarding the maintaining privacy during examination and treatment were another effecting factors to select the private and public sector oral health care services.

Patel, 2014 showed that the majority of patient $(80 \%)$ had good experience and $12 \%$ and $8 \%$ of patients had fair and poor experience with the dentist respectively at public oral health care sector in India. The current study showed that the $49.11 \%$ of patients' satisfaction in the private sector and $23.54 \%$ in the public sector while $26.08 \%$ were not satisfied in public sector on the ability of receiving service from the dentist and other staff. Further, Study on public attitude towards selection of dental service by Moshkelgosha et al., 2014 identified the poor reputation has a negative impact on the selecting oral health care sector. However, this study showed that there is a positive impact in public sector and negative impact on public sector on patients' perception regarding the attention and respect paid on their health by staff.

The cost of treatment for oral health care services has been considered as major constrain in many developed and developing countries with different health care systems (Ajayi \& Arigbede, 2012; Goedhart et al, 1996, Chu et al., 2001). Furthermore, the cost of health care delivery is an important factor that determines the selection of service provider (Moshkelgosha et al., 2014; Pinto et al., 2014). A study on public perceptions and experiences on private and public oral health care service in the United Kingdom showed that greater satisfaction with certain aspects of private care than the public system, although the cost of treatment is relatively high (Hancock et al., 1999). Present study at Mahiyanganaya DS area study showed patients who were satisfied with the cost in the private sector $(42.36 \%$ ). The percentage of patients who were not satisfied with cost was $38.91 \%$. This finding might helpful for reviewing the cost of dental services in private dental clinic and to make treatment fees more affordable to the public.

Present study at Mahiyanganaya DS area showed that $40.21 \%$ of patients were more satisfied on revisit to the current dental clinic in private oral health care sector, this rate in the public sector is $5.93 \%$. This may be related to the cost of treatment, quality of dental care, up-to-date care, modern equipped dental clinic, availability of friendly staff and convenient appointment, friendly health team as discussed previously (Awliya, 2003, Jannati et al., 2013, Al - Johara \& Al-Hussyeen, 2010). Even through cost is one of barrier in the private sectors, patents were prepared to re-visit in the private sector clinics due to discussed of all other above factors. Therefore, further improvement of the oral health care delivery system is needed to ensure high quality of treatment and to reduce the negative outcome of the treatment.

\section{CONCLUSION AND RECOMENDATION}

The study revealed that the socio demographic factors (age, gender, level of education, family income, mode of transport and distance from resident to oral health care sector) may have significant influence in selection of private or public oral health care services provider. In additionally, Perceived patient care relationship, perceived quality of oral health care services, perceived responsiveness of oral health care services and cost of treatment are important factors related to oral health care services when selecting either private or public sector oral health care service sector. Further, it shows that the most patients dissatisfied with the environment cleanliness in the clinic set up at public oral health care sector. Therefore, more attention has to pay for this factor.

Today, patients' perception, concept and experience with oral health care services are recognized as main measures of the quality assurance programs. The evaluation of patient satisfaction is to be part of the oral health care delivery. Consequently, periodic clinical audits, patient satisfaction survey in both private and public sector oral health care sector are essential to carry out to identify lacking area is vital for the improvement.

Most patients were most satisfied with the functional quality of the private sector oral health care sector. To improve public oral health care sector, need to increase awareness, knowledge, attitudes and practices health care staff to in relation to functional quality furthermore ( $\mathrm{Eg}$ communication skills, responsiveness etc.). However, cost of oral health care is one of the important factors for selection of people's choice of dental clinic. Therefore, transparency of fees in oral cares services has to improve via introducing cost escalation mechanisms or cost regulation mechanisms. Further, this study indicated that the female were more used oral health services in both private and public sector. Therefore, it is necessary to improve health seeking behavior of male via health education, promotion and awareness.

It is recommended to have extended OPD hours $(5 \mathrm{pm}$ to $8 \mathrm{pm})$ in the public sector. This after working hours is more suitable for the workers. Additionally, improvement in public oral health care facility can be achieved by the enhancing the feasibility and easy access to the dental clinic and improving the cleanness of environment. According to patients' perception regarding public sector, it is necessary to improve the availability of dental equipment, dental materials, and other facilities. Then public sector oral health care 
staff can perform Root Canal Treatment (RCT), basic prosthetic treatment and basic orthodontic treatments. If the public oral health care sector can introduce methods to selection of choice of provider, it will help to improve overall quality, safety, assurance and satisfaction of the patient.

This study assesses the factors affecting selection of private or public sector oral health care services in Mahiyangana DS area. More such studies are necessary to carry out across the country in the areas with the different socio-economic background in near future. Therefore, an amalgamation of the above literature could be enhanced and used to improve the oral health care service provided by private and public sector in Sri Lanka.

\section{ETHICAL IMPLICATIONS}

Ethical clearance for the study was obtained from the Ethical review committee of the Faculty of Medicine, University of Colombo

\section{REFERENCES}

Abeysekara, W.P.M.M. (2010). Bypass of local oral health care institutions by outpatient dental clinic attendees at the general hospital Polonnaruwa. MSc. (Community Dentistry), Postgraduate Institute of Medicine, University of Colombo.

Ajayi, D.M. \& Arigbede A.O. (2012). Barriers to oral health care utilization in Ibadan, South West Nigeria. Afr Health Sci., 12, 507513.

Akilendran, K. (2014). Factors influencing selection of private and public outpatient department services in Vavuniya District. (Unpublished MSc thesis), Postgraduate Institute of Medicine, University of Colombo.

Al-Johara, \& Al-Hussyeen, (2010). Factors affecting utilization of dental health services and satisfaction among adolescent females in Riyadh City. The Saudi Dental Journal, 22, 19-25.

Annual Health Bulletin. (2012). Ministry of Healthcare and Nutrition, Colombo;Sri Lanka.

Awliya, W.Y. (2003). Patient satisfaction with the dental services provided by the Dental College of King Saud University. Saudi Dental Journal. 15, 11-16.

Bollagala, A.D.(2010). Prevalence of common oral health problems and utilization pattern of oral health care services by institutionalized elderly in Cilombo Municipal Council area. (Unpublished MSc thesis), Postgraduate Institute of Medicine, University of Colombo.

Brennan, D.S., Luzzi, L. \& Roberts-Thomson, K.F. (2008). Dental service patterns among private and public adult patients in Australia. BMC Health Services Research. 2008 Jan 3; 8(1):1

Chu, C.H., Yeung, C.Y. \& Lo, E.C. (2001). Monitoring patient satisfaction with university dental services under two fee-paying systems. Community Den. Oral Epidemiol 29, 390-398.

De Alwis, S.S., Fernando, T and Rannan-Eliya, R.P. (2011). Sri Lanka Health Accounts: National Health Expenditure $1990-2008$. Health Expenditure Series No.2. Institute for Health Policy, Colombo, Retrieved from http://www.ihp.lk/publications/docs/HES1102.pdf [Accessed 31/12/2015].

De Silva, M.D.K. (2012). Dental workforce planning for Sri Lanka. (PhD thesis). School of Magagement, University of Southampton, UK.

De Silva, M.D.K., Brailsford, S.C. \& Ekanayake, A.N.I. (2010). The distribution of private sector dental practitioners and clinics in Sri Lanka. Sri Lanka Dental Journal, 40 (01), 7-15.

Eustaquio, M.-E., Montiel J.-M., and Almerich, J.-M. (2010). Oral health survey of the adult population of the Valencia region (Spain). Med Oral Patol Oral Cir Bucal. 2010 , 15(3), 538-544.

Fernando, W.S.G. (2007). Common oral disease: knowledge and practices among public health Midwives in Puttlam District. (Unpublished MSc thesis), Postgraduate Institute of Medicine, University of Colombo. 
Goedhart H., Eijkman M.A. \& ter Host G. (1996). Quality of dental care: the view of regular attenders. Community Den. Oral Epidemiol, 24, 28-3.

Govindaraj, R., Navaratne, K., Cavagnera,E. \& Serieshadri, S.R.(2014). Health care in Sri Lanka: What can the private health sector offer? Health, Nutrition, and Population (HNP) Discussion Paper. Retrieved from http://docplayer.net/1001009-Health-care-in-sri-lanka.html (Accessed 07/11/2015).

Hancock, M., Calnan, M. \& Manley, G. (1999). Private or NHS general dental services in the United Kingdum? A study of public perceptions and experiences. J. Public Health Medicine, 21(4), 415-420.

Iqbal, M., Jameel, A., Girach, M.M. \& Murtaza, (2014). Factors affecting patients' choice of dental services. Pakistan Oral \& Dental Journal, 34(4), p. 691-695.

Jannati, A., Bahrami, M.A., Gholizadeh, M., Alizadeh, L.,Khodayari, M.T. (2013). A survey of factors affecting patients' decision in selecting Governmental and Private Hospitals in Tabriz, Iran. J Tourism Res Hospitality, 2,(1), 1-4.

Mahrous, M.S. and Hifnawy, T.(2012). Patient satisfaction from dental services provided by the College of Dentistry, Taibah University, Soudi Arabbia. J. Taibah University Medical Sciences. 7(2), 104-109.

Malmö University. (2009). Oral Health Country/Area Profile Project (CAPP).[online] Retrieved from http://www.mah.se/capp/ [Accessed 18/07/2016]

Moshkelgosha,V., Mehrzadi, M. \& Golkari, A.(2014). The Public Attitude Towards Selecting Dental Health Centers . J Dent Shiraz Univ Med Sci., 15(3), 129-134.

Pallegedara, P.M.M.C. (2003). Prevalence of tooth loss and its impact on the elderly. (Unpublished MSc thesis), Postgraduate Institute of Medicine, University of Colombo.

Perera, I., Kruger, E. \& Tennant, M. (2012). GIS as a decision support tool in health information: Spatial analysis of public dental care services in Sri Lanka. J. Health Informatics in Developing Countries, 6(1), 422-433.

Perera,I.R. (2001).Oral health related quality of life among elderly in Moratuwa MOH area. (Unpublished MSc thesis), Postgraduate Institute of Medicine, University of Colombo.

Petal, J.Y. (2014). A study on evaluation of patient satisfaction with dental health care services. International Journal of Scientific and Research Publications. 4(8), 1-4.

Pinto, R.S., Abreu, M.H.N.G., Vargas, A.M.D. (2014). Comparing adult users of public and private dental services in the state of Minas Gerais, Brazil. BMC Oral Health 14, 100-113

Rankin, J.A. and Harris, M.B. (1985). Patients' preference for dentist behaviour. J Am Dent Assoc., 110, 323-326.

The Performance Report and Annual Accounts of District Secretariat Badulla. (2013).

Retrieved from http://www.parliament.lk/uploads/documents/paperspresented/performance_report_district_secretariat_badulla_2013.pdf [Accessed 24/12/2015]

Varatharajan, V., Sumanaweera, N.P., Samarage, S.M., Jayasekara, A. (2005). Stake holder perspective on health and healthcare in Sri Lanka. Colombo: National Commission on Macroeconomics and Health.Sri Lanka: Ministry of Healthcare and Nutrition, Government of Sri Lanka.

Wickramasingh, D. (2011). Utilization patterns of oral health care services by mothers attending antenatal clinic in Dehiwala Medical Officer of Health area. (Unpublished MSc thesis), Postgraduate Institute of Medicine, University of Colombo. 


\section{AUTHORS}

First Author - Y.M.S.S. Yapa, MD, Postgraduate Institute of Medicine, University of Colombo, ymssyapa@ gmail.com

Second Author - S.N. Kumari, PhD, Department of Science and Technology, Faculty of Applied Sciences, Uva Wellassa University, Badulla, Sri Lanka (if any) and email address, sandya@uwu.ac.lk

Third Author - S.R. Jayasinghe, BSc, Department of Science and Technology, Faculty of Applied Sciences, Uva Wellassa University, Badulla, Sri Lank, shani91jaya@yahoo.com

Fourth Author - T.H.N.G. Amaraweera, PhD, Department of Applied Earth Sciences, Faculty of Applied Sciences, Uva Wellassa University, Badulla, Sri Lanka, gayani@uwu.ac.lk 